\title{
A study on association of thrombocytopenia with pregnancy induced hypertension
}

\section{Kasturi V. Donimath, Annapurna M. Sambrani*, Pratik M. Rathod}

Department of Obstetrics \& Gynaecology, Karnataka Institute of Medical Sciences, Hubli, Karnataka, India

Received: 18 January 2016

Revised: 25 January 2016

Accepted: 15 February 2016

\section{*Correspondence:}

Dr. Annapurna M. Sambrani,

E-mail: anupamasambrani@gmail.com

Copyright: $\odot$ the author(s), publisher and licensee Medip Academy. This is an open-access article distributed under the terms of the Creative Commons Attribution Non-Commercial License, which permits unrestricted non-commercial use, distribution, and reproduction in any medium, provided the original work is properly cited.

\begin{abstract}
Background: Hypertension is common complication of pregnancy and contributes significantly to maternal and perinatal morbidity and mortality. With incidence of 5-7\% of all pregnancy. Platelet count is the most simple and economical method of prediction of PIH, way before the derangements in PT, PTT and TT occur. This study sought the importance of platelet count as the most consistent and reliable method in predicting the severity of PIH. The aim and objectives of the study was to correlate severity of PIH with degree of thrombocytopenia and the degree of thrombocytopenia with fetal and maternal outcome.

Methods: Prospective observational study was done during November 2014 to June 2015. A total of 100 cases were included in this period that was diagnosed as PIH. Investigations like platelet count, LFT, RFT, PT were done. Observations were tabulated, analyzed and conclusions were drawn.

Results: $66 \%$ of all the cases had severe preeclampsia and 56\% had thrombocytopenia. There was very high significant relationship between the degree of thrombocytopenia with the severity of the PIH (at $\mathrm{p}<0.001$ ). 12\% of the fetuses had IUD, $10 \%$ had IUGR, $4 \%$ died after birth and 2\% had severe birth asphyxia. $5 \%$ of the mothers had DIC, $3 \%$ showing HELLP syndrome, and $1 \%$ died.

Conclusions: Thrombocytopenia is the most common complications of PIH and at times is life threatening. Therefore, platelet count can be used as an early, simple, and rapid test to assess the severity of pre eclampsia and prevent progression to HELLP syndrome and DIC.
\end{abstract}

Keywords: PIH, Pre-eclampsia, Thrombocytopenia, Mortality, Morbidity, Economical, Reliable, Fetal/Maternal outcome, IUD, IUGR, DIC, HELLP

\section{INTRODUCTION}

PIH is the most common medical disorder of pregnancy that leads to a complicated multi-organ failure in the mother. It is one of the most common causes of both maternal and neonatal morbidity. ${ }^{1}$

It is a global problem and complicates approximately 10$17 \%$ of pregnancies. The incidence of PIH in India ranges from $5 \%$ to $15 \%{ }^{2}$

Preeclampsia is defined as a multisystem disorder occurring in pregnancy and the puerperium which is characterized by development of hypertension of 140/90
$\mathrm{mmHg}$ and above after the 20th weeks of gestation in a previously normotensive patient. ${ }^{3}$

Preeclampsia is primarily characterized by hypertension and proteinuria. [ $>300 \mathrm{mg} / 24$ hours]. Preeclampsia may also be accompanied by rapid weight gain and oedema, appearance of coagulation or liver function abnormalities. $^{4}$

Severe preeclampsia is characterized by blood pressure $>160 / 110 \mathrm{~mm} \mathrm{Hg}$, nephrotic range proteinuria, sudden oliguria, neurologic symptom like headache, hyperreflexia and laboratory tests demonstrating thrombocytopenia, haemolysis, or abnormal liver 
function, although the magnitude of proteinuria alone as a predictor of severity has been questioned. ${ }^{5}$

Profound changes in the coagulation and fibrinolytic system occur during normal pregnancy causing a hypercoagulable state. There is a definite exaggeration of the hypercoagulable state of pregnancy during Pregnancy Induced Hypertension (PIH). Out of all the haematological abnormalities that occur in PIH, thrombocytopenia is the most common seen to occur in $11 \%$ to $29 \%$ of patients. ${ }^{6}$ These pregnancies also are associated with qualitative changes suggesting increased platelet production and destruction. There is a shortened platelet life span, increased numbers of megakaryocytes in the bone marrow, and an increased number of immature platelets seen in the peripheral blood smear. ${ }^{7}$ The frequency and intensity of maternal thrombocytopenia varies and is dependent on the intensity of the disease process and duration of PIH syndrome. ${ }^{8}$ Overt thrombocytopenia, defined by a platelet count less than $100,000 / \mathrm{L}$, indicates severe disease. ${ }^{9}$ In general, the lower the platelet counts, the higher the maternal and fetal morbidity and mortality. In most cases, delivery is indicated because the platelet count continues to decrease. A variety of haematological abnormalities may occur in women with PIH of which thrombocytopenia is the most common. There is no screening test that would help in identifying which pregnancy will be associated with PIH or assess its severity. ${ }^{10}$

Some investigators have proposed biochemical markers to predict the severity of PIH like Placental tissue protein 13 and Endoglin's; but these tests cannot be used for simple, low-cost screening. Therefore, there is a need to identify a simple test specifically designed for routine use in a hospital environment in particular those suitable at a rural setup. ${ }^{11}$

This study was done to estimate the incidence of thrombocytopenia in pregnant women diagnosed with $\mathrm{PIH}$ and to correlate the severity of PIH with the degree of thrombocytopenia.

\section{METHODS}

Prospective observational study was carried out in the department of Obstetrics and Gynaecology, KIMS Hubli from November 2014 to June 2015. A total of 100 cases were included in this study period who were diagnosed as $\mathrm{PIH}$ with BP >140 mmHg Systolic and >90 $\mathrm{mmHg}$ and Diastolic after 20 weeks of gestation were included in the study. Clinical details were collected from all the cases which included the demographic data, symptoms, examination findings, and investigations (platelet count, LFT, RFT, PT, INR) done were analysed, effects on multiple factors were studied, 'P' values were statistically derived and evaluated.

\section{Inclusion criteria}

- Gestational age more than 34 weeks.

- All newly diagnosed PIH patients.

\section{Exclusion criteria}

- Gestation age <34 weeks.

- Pre-existing renal disease, diabetes.

- Pre-existing endocrine disorders.

- $\quad$ ITP, TTP, APLA, SLE.

- Patients on medications which are known to cause thrombocytopenia.

- Patients with chronic hypertension.

\section{Study method}

- $\quad$ PIH was classified into MILD and SEVERE, which were predefined as

○ Mild: Gestational hypertension, Mild pre eclampsia.

- Severe: Severe pre eclampsia, Imminent and Antepartum eclampsia.

- A detailed history, clinical findings and relevant investigation were noted as per pro forma.

- Whole blood sample was obtained after informed consent, under aseptic precaution by venepuncture of anterior cubital vein into EDTA and PLAIN bulbs and sample was tested for platelet counts, PT, INR, RFT and LFT.

- The details were recorded as per pro forma and analyzed to fulfill the aims and objectives of the study.

- The data was then tabulated in MS Excel, correlation tests like chi square/ Fischer exact were applied to the relevant tabulated data and the same was analyzed in SPSS 17.0.

\section{RESULTS}

\section{Tests of significance}

Calculated $\mathrm{x}^{2}=35.651$.

$\mathrm{P}$ value for the above at degree of freedom 1 is $<0.001$, implying its high significance between $\mathrm{PIH}$ and Thrombocytopenia.

It is observed from the above table that out of:

- Out of 8 cases of gestational hypertension, no cases showed thrombocytopenia.

- Out of 26 cases of MILD pre-eclampsia, 4 showed mild degree, 1 showed moderate degree of thrombocytopenia, with rest 21 showing normal platelet counts.

- Out of 29 cases of severe PE, 11 showed mild degree, 3 moderate degree, 1 showed severe degree 
of thrombocytopenia, with rest showing normal values.

- Out of 25 cases of imminent eclampsia, 9 showed mild, 14 showed moderate and 1 showed severe degree of thrombocytopenia with 1 showing normal counts.

- Out of 12 cases of antepartum eclampsia, 2 showed mild, 6 moderate degree, 4 showed severe degree of thrombocytopenia.

Table 1: Association of thrombocytopenia with PIH.

\begin{tabular}{|lllllll|}
\hline Thrombocytopenia & $\begin{array}{l}\text { Antepartum } \\
\text { eclampsia }\end{array}$ & $\mathrm{GH}^{*}$ & $\begin{array}{l}\text { Imminent } \\
\text { eclampsia }\end{array}$ & Mild PE** & Severe PE \\
\hline Normal $(1.5-5$ lakh/ mm3) & 0 & 8 & 1 & 21 & 4 & 14 \\
\hline Mild $(1-1.5$ lakh/mm3) & 2 & 0 & 9 & 1 & 11 & 26 \\
\hline Moderate(0.5-1 lakh/ mm3) & 6 & 0 & 14 & 0 & 3 & 1 \\
\hline Severe $(<50000 / \mathrm{mm} 3)$ & 4 & 0 & 1 & 26 & 29 & 6 \\
\hline Total & 12 & 8 & 25 & & 100 \\
\hline
\end{tabular}

*Gestational hypertension; **pre-eclampsia; ***pregnancy incused hypertension.

Table 2: PIH vs fetal outcome.

\begin{tabular}{|lllllll|}
\hline & & \multicolumn{3}{c|}{ Fetal outcome } & & Total \\
\hline PIH & Died & Good & IUD & IUGR & Severe birth asphyxia & Totepartum eclampsia \\
\hline GH & 2 & 4 & 3 & 1 & 2 & 12 \\
\hline Imminent eclampsia & 0 & 8 & 0 & 0 & 0 & 25 \\
\hline Mild Pre eclampsia & 2 & 12 & 6 & 5 & 0 & 26 \\
\hline Severe Pre eclampsia & 0 & 23 & 1 & 2 & 0 & 29 \\
\hline Total & 4 & 25 & 2 & 2 & 0 & 100 \\
\hline
\end{tabular}

It was observed from the above table that $72 \%$ of the babies were born without any complications, followed by $12 \%$ of the fetuses which had IUD. $10 \%$ of the neonate were IUGR, with another $4 \%$ died after birth and $2 \%$ with severe birth asphyxia but alive.

Table 3: PIH vs fetal outcome.

\begin{tabular}{|lllll|l|}
\hline PIH & Fetal outcome & GOOD & HELP & Total \\
\hline Antepartum eclampsia & 0 & DIC & GOOD & 2 & 12 \\
\hline GH & 0 & 2 & 8 & 0 & 8 \\
\hline Imminent eclampsia & 1 & 0 & 8 & 1 & 25 \\
\hline Mild Pre eclampsia & 0 & 2 & 21 & 0 & 26 \\
\hline Severe Pre eclampsia & 0 & 0 & 26 & 0 & 29 \\
\hline Total & 1 & 5 & 91 & 3 & 100 \\
\hline
\end{tabular}

It was observed that $91 \%$ of the mothers had no complications. $5 \%$ manifested as DIC with $3 \%$ showing HELLP syndrome and one reporting to had cardiac arrest and died.

\section{DISCUSSION}

Pre-eclampsia is one of the major maternal and perinatal mortality and morbidity worldwide, particularly in developing countries. $^{12}$ Preeclampsia affects approximately $6 \%$ of all the pregnancies, more often in 
primigravidas in the age group of 20-30 years. Preeclampsia accounts $17.6 \%$ of maternal deaths in United States. $^{12}$

Approximately $50 \%$ of patients with preeclampsia will develop thrombocytopenia. Severity will be usually proportionate to that of the underlying pathology .But in few cases, onset of thrombocytopenia precedes other manifestations of pre-eclampsia. ${ }^{13}$ Though the pathogenesis of thrombocytopenia in patients with preeclampsia is not well understood, recent studies suggest that megakaryocytopoiesis impairment as a pathogenic factor. ${ }^{14-16}$

In our present study a total of $100 \mathrm{PIH}$ cases who were evaluated majority cases were in the age group of 20-22 years with the mean of 22.74 next being 22-25 years as compared to Vamsheedhar et al, Shivkumar et al and Prakash J et al studies with mean age of 24.57, 24.3 and 24.75 respectively. ${ }^{1,17,19}$ Intrauterine deaths, intrauterine growth restriction, prematurity and perinatal asphyxia are common complications in the baby born to mother of pregnancy induced hypertension. ${ }^{18}$

In the present study $65 \%$ of PIH were primigravidas and $57 \%$ belonged to $37-40$ weeks gestational age, $66 \%$ cases were severe preeclampsia (severe pre eclampsia + imminent eclampsia + antepartum eclampsia) and 50\% cases showing thrombocytopenia (26 mild +24 severe degree).

\section{CONCLUSIONS}

Analysing the above observations we can arrive at a conclusion that thrombocytopenia worsens as $\mathrm{PIH}$ progresses from gestational hypertension to eclampsia, so it is advised to monitor platelet count, which is simple, economical and rapid investigation to monitor the progress of PIH. Estimation of platelet count thus, can be used as an early, simple, and rapid procedure in the assessment of severity of pre eclampsia and prevent progression to HELLP syndrome and DIC.

\section{ACKNOWLEDGEMENTS}

We acknowledge the help provided by our institute's statistician and Ms. Geetha who helped with typing.

Funding: No funding sources

Conflict of interest: None declared

Ethical approval: Not required

\section{REFERENCES}

1. Sivakumar S, Bhat BV, Badhe BA. Effect of pregnancy induced hypertension on mothers and their babies. Indian J Pediatr. 2007;74:623-5.

2. Anand S, Kirshnanand. Perinatal outcome in growth retarded babies born to normotensive and hypertensive mothers: A prospective study. People's J Sci Res. 2012;5:24-8.

3. Sibai BM. Hypertension in pregnancy. Clinical Obstet Gynecol. 1999:421-36.

4. Marshall D. Lindheimer, Sandra J. Taler, and F. Gary Cunningham. Hypertension in pregnancy. Journal of the American Society of Hypertension. 2008;2:484-94.

5. Menzies J, Magee LA, MacNab YC, Ansermino JM, Li J, Douglas MJ, et al. Current CHS and NHBPEP criteria for severe preeclampsia do not uniformly predict adverse maternal or perinatal outcomes. Hypertens Pregnancy. 2007;26:447-62.

6. Gibson G, Hunter D, Neame PB, Kelton JG. Thrombocytopenia in pre-eclampsia and eclampsia. Semin Thromb Hemost. 1982;8:234-47.

7. Burrows RF, Hunter DJS, Andrew M, Kelton JG. A prospective study investigating the mechanism of thrombocytopenia in preeclampsia. Obstet Gynecol. 1987;70:334-8.

8. Heilmann L, Rath W, Pollow K:H hemostatic abnormalities in patients with severe preeclampsia. Clin appl thromb hemost. 2007;13:285.

9. Leduc L, Wheeler JM, Kirshon B, et al: Coagulation profile in sever preeclampsia. Obstet gynecol. 1992;79:14.

10. Meshram DP, Chavan YH, Kadam PN, Panchal MG, Ramteke DJ. Maternal and foetal outcomes in pregnancy induced hypertension - A hospital based study. Int J Pharm Sci Invention. 2014;3:23-6.

11. Andrews L, Haridas N, Vaishnav S, Desai K. Biochemical and hematological investigations in pregnancy induced hypertension. J Cell Tissue Res. 2012;12:3009-13.

12. Vigil D, Gracia U. Pregnancy complicated by preeclampsia]eclampsia with HELLP syndrome P. International International Journal of Gynecology \& Obstetrics. 2001;72:17-23.

13. Langer A, Villar J, Tell K, Kim T, Kennedy S. Reducing eclampsia-related deaths - a call to action. Lancet. 2008;371:705-6.

14. McCrae KR, Samuels P, Schreiber AD. Pregnancyassociated thrombocytopenia: pathogenesis and, management. Blood. 1992;80:2697-714.

15. Dame C. Thrombopoietin in thrombocytopenias of childhood. Sem Thromb Haemost. 2001;27:215-2.

16. Roberts IA, Murray NA. Neonatal thrombocytopenia: new insights into pathogenesis 
and implications for fetal management. Curr Topics Micro Immunol. 2001;13:16-23.

17. Prakash J, Pandey LK, Singh AK, Kar B. Hypertension in pregnancy: Hospital based study. J Assoc Physicians India. 2006;54:273-8.

18. Sandhya S, Vishnu BB, Bhawana AB. Effect of pregnancy induced hypertension on mothers and their babies. Indian J Pediatr. 2007;74:623-5.

19. Annam V, Srinivas K, Yatnatti SK, Suresh DR. Evaluation of platelet indices and platelet counts and their significance in preeclampsia and eclampsia. Int J Biol Med Res. 2011;2:425-8.

Cite this article as: Donimath KV, Sambrani AM, Rathod PM. A study on association of thrombocytopenia with pregnancy induced hypertension. Int J Reprod Contracept Obstet Gynecol 2016;5:808-12. 